\title{
A conclusão da educação superior por cegos e a psicologia de Vygotski: a ponta do iceberg
}

\author{
Bento Selau* \\ Magda Floriana Damiani**
}

\section{Resumo}

Este trabalho objetiva apresentar os fatores relacionados à conclusão da educação superior, por parte de um grupo de estudantes cegos, a partir de seus próprios pontos de vista. Realizaram-se estudos de casos com nove sujeitos, sendo os dados coletados por meio de entrevistas narrativas e análise documental e submetidos a um processo de análise textual discursiva. O referencial que embasou a pesquisa foi o da Psicologia Histórico-Cultural de Vygotski. Os achados apontam fatores que dificultaram a conclusão do ensino superior - como o processo de seleção, que ignora as necessidades dos cegos; a falta de preparo das instituições para atender os deficientes; os preconceitos de docentes. Ao mesmo tempo, indicam fatores que favoreceram essa conclusão - como o auxílio aos cegos por parte de docentes e familiares, a tomada de consciência sobre a importância da formação universitária para suas vidas futuras gerando vontade para alcançá-la.

Palavras-chave: Educação Superior. Cegueira. Psicologia Histórico-Cultural.

\footnotetext{
* Doutor em Educação pela Universidade Federal de Pelotas (UFPel). Professor do Programa de Pós-Graduação em Educação da Universidade Federal do Pampa (UNIPAMPA).

*** Doutora em Educação pela University of London, Inglaterra. Professora da Faculdade de Educação e do Programa de Pós-Graduação em Educação da Universidade Federal de Pelotas (UFPel).
} 


\section{Introdução}

$\mathrm{O}$ acesso e a permanência de pessoas com cegueira ${ }^{1}$ na educação superior brasileira são temas que chamam a atenção, nos dias atuais, sobretudo pelo reduzido número de cegos que frequentam essa etapa do processo de escolarização. De acordo com o antepenúltimo resumo técnico do censo da educação superior, do ano de 2009 (BRASIL, 2010), realizado pelo Instituto Nacional de Estudos e Pesquisas Educacionais Anísio Teixeira (INEP), havia, nesse ano, 20.019 alunos com alguma deficiência matriculados no ensino superior, o que correspondia a $0,34 \%$ do total de alunos que cursam essa etapa da escolarização. Entre eles, cerca de 2.602 (13\%) eram cegos ${ }^{2}$.

A inclusão de pessoas cegas na educação superior, em nosso país, é recente ${ }^{3}$. Como mostram os dados acima, apenas um pequeno número de cegos tem conseguido acesso à universidade. Além disso, esse grupo "vem encontrando dificuldades em permanecer e concluir os cursos" (OKA e NASSIF, 2010, p. 412).

A presença de alunos cegos na educação superior brasileira, aparentemente, não deveria significar a imposição de maiores dificuldades a esses estudantes ou ao corpo docente das universidades, uma vez que se conhecem diferentes estratégias de ensino e recursos tecnológicos que favorecem as aprendizagens dos cegos (o sistema de leitura-escrita braille, os programas computacionais leitores de tela, os gravadores de voz etc.). Entretanto, sem deixar de lado a evidente necessidade de se fazer adaptações instrumentais, em função da necessidade de utilizar esses métodos e recursos pedagógicos, com o intuito de favorecer a interação do cego com o conteúdo abordado em cada componente curricular, não é suficiente dar atenção apenas a esses métodos e recursos para fomentar a participação e a consequente conclusão da educação superior pelos cegos. Discutir a inclusão dos cegos na educação superior e a possibilidade de que concluam seus cursos de graduação, somente a partir dos aspectos materiais e práticos a elas associados é como olhar para um iceberg apenas observando a parte que está para fora d'água, imaginando que aquela grande massa de gelo flutuante é composta somente pelo que se vê, sem ter a consciência de que a parte imersa é muito maior que a emersa e a compõe. Este trabalho visa desvelar alguns aspectos dessa parte submersa.

Com foco centrado nos relatos verbais e em escritos de estudantes cegos, egressos da educação superior, a pesquisa que aqui se apresenta, a qual embasou uma tese de doutorado da área da Educação (SELAU, 2013), objetivou descrever como um grupo de cegos explica a sua conclusão da educação 
superior. A análise foi especialmente centrada nos aspectos psicológicos ligados a tal conclusão e, para tanto, foram utilizadas as ideias de Lev Semenovitch Vygotski ${ }^{4}$.

A relevância desta pesquisa está relacionada, em primeiro lugar, à necessidade de se desenvolver estudos referentes à inclusão de cegos na educação superior do Brasil, principalmente pelas dificuldades que tal tarefa se lhes impõem. Rodrigues (2004) lembra que a universidade ainda não está pronta para atender a todos e que precisa constituir-se em um espaço que privilegie discussões a respeito de práticas que favoreçam a consumação de uma política inclusiva dentro de seus muros.

Apesar de se considerar que as políticas de inclusão (BRASIL, 2008, 2011, 2013b, 2015) apontam para mudanças nas instituições de educação superior - em termos de organização e de prática pedagógica - e no estabelecimento dos direitos educacionais do deficiente, Siqueira e Santana (2010, p. 135) compreendem que "existe uma lacuna entre as diretrizes legais existentes e a efetivação do acesso e permanência dos alunos com necessidades educativas especiais", principalmente nesse nível educacional. Há necessidade de definição, por parte das universidades, sobre suas políticas de acessibilidade e inclusão educacional, para além do Programa Incluir (BRASIL, 2013b), conforme comentam Selau e Hammes (2014, p. 14-15):

[...] uma política institucional de educação inclusiva, focada em suas metas e características próprias, articulando toda a comunidade acadêmica, permite [...] que se compreenda que a instituição de ensino superior tem um compromisso com a proposta inclusiva e, de fato, pensa e repensa as suas ações neste âmbito.

A pesquisa sobre a inclusão de cegos nas universidades é relevante, em segundo lugar, porque pode colaborar para que se amplie a discussão dessa temática em nosso país, onde há poucos estudos a esse respeito, com base em Vygotski. Segundo Caiado e Garcia (2008), por exemplo, os participantes da assembleia do Grupo de Trabalho 15 da Associação Nacional de Pós-Graduação e Pesquisa em Educação (ANPEd), em 2006, comentavam que existia uma lacuna referente a publicações sobre a temática da deficiência visual, em todos os níveis do processo de escolarização. Também a análise elaborada por Freitas (2004) sobre os trabalhos fundamentados no pensamento de Vygotski, os quais podem ser encontrados nos anais das reuniões anuais da ANPEd de número 21 a 26 (entre 1998 e 2003), mostrou que não havia textos referentes ao deficiente visual.

A seguir, apresentam-se os procedimentos metodológicos adotados na investigação aqui relatada e seus achados, em interlocução com as outras pesquisas, que enfocaram, concomitantemente, a experiência de cegos no ensino superior e as ideias de Vygotski. Por fim, são apresentadas as considerações finais do trabalho. 


\section{Procedimentos metodológicos}

Este estudo ancorou-se em uma abordagem de natureza qualitativa, assumindo a forma de estudos de casos (BOGDAN; BIKLEN, 1994; LÜDKE; ANDRÉ, 1986). Os participantes foram nove sujeitos cegos - seis do sexo masculino $(\mathrm{SM})$ e três do sexo feminino $(\mathrm{SF})^{5}$. Seguem alguns dados sobre os cursos que concluíram e sua atuação profissional, à época da coleta de dados:

- SM1: bacharelado em Ciências Sociais Jurídicas (colação de grau: 1999); exerce a profissão de advogado;

- SM2: licenciatura em Letras (colação de grau: 1995); faleceu alguns meses após a coleta de dados;

- SM3: bacharelado em Fisioterapia (colação de grau: 1983) e licenciatura em Letras/Português (colação de grau: 1994); atua como professor;

- SM4: bacharelado em Ciências da Computação (colação de grau: 2006); exerce a função de analista de suporte;

- SM5: bacharelado em Fisioterapia (colação de grau: 1984); atua como fisioterapeuta;

- SM6: diferentemente dos outros, este sujeito já era falecido. O interesse por conhecer a sua história e utilizar seus dados para cumprir o objetivo da pesquisa ocorreu por ser ele Walkírio Ughini Bertoldo ${ }^{6}$ (1930-1998) - o primeiro cego a concluir a educação superior em Direito, no território nacional (colação de grau: 1957), fato atestado em diversos documentos (SELAU; DAMIANI, 2014; UM..., 1958);

- SF1: licenciatura em Letras/Inglês (colação de grau: 2009); atua como professora;

- SF2: licenciatura em História (colação de grau: 2005); atua como assistente administrativa;

- SF3: licenciatura em Pedagogia (colação de grau: 2011); exerce a profissão de professora.

Os critérios de seleção dos participantes eram: ser egresso da educação superior e ser cego desde o ingresso nesta. Os sujeitos foram localizados por meio da rede de colaboração dos pesquisadores e seus colegas de trabalho.

Os dados foram coletados por meio de entrevistas narrativas (exceto os referentes a Bertoldo, SM6) e análise documental. Combinaram-se dois instrumentos para dar validade à pesquisa (OLLAIK; ZILLER, 2012).

O uso de entrevistas foi considerado crucial, uma vez que propiciou o mapeamento e a compreensão das relações entre atores sociais e sua situação de vida, tal como argumentam Bauer e 
Gaskell (2002). Além disso, a entrevista tem sido largamente utilizada, com sucesso, em diversas pesquisas das quais participaram sujeitos cegos (BAZON, 2009; OLIVEIRA, 2008; OLIVEIRA, 2007; RAPOSO, 2006; DELPINO, 2004; CAIADO, 2003).

Quanto à análise documental, seu foco foram textos, solicitados aos participantes, logo após as entrevistas. Pediu-se a eles que escrevessem uma redação, com extensão mínima de duas páginas e máxima indefinida, com o seguinte tema: “o fator (ou fatores) que influenciou (influenciaram) você a permanecer e a concluir a educação superior". Esse instrumento já foi utilizado por Raposo (2006), em pesquisa que envolveu a participação de sujeitos universitários com deficiência visual, tendo como principal aporte teórico as concepções vygotskianas. A autora argumenta que o uso da redação proporciona aos participantes a possibilidade de se expressarem com mais liberdade, tendo sido, por isso, avaliado positivamente em sua pesquisa.

No tocante aos procedimentos metodológicos referentes a Bertoldo, utilizaram-se as sugestões propostas por Pujadas Muñoz (2002), quanto ao método biográfico e às possibilidades do uso de biografias nas ciências sociais. Os dados relativos a este sujeito foram coletados por meio de entrevistas com dois de seus ex-colegas de faculdade e de uma de suas irmãs, todos videntes. Junto a esses informantes, procurou-se obter informações semelhantes àquelas coletadas diretamente com os sujeitos cegos. À sua irmã também foi solicitada a escrita de uma redação relatando "a história de vida do seu irmão e os possíveis fatores que o influenciaram a permanecer e a concluir a educação superior”.

Após as transcrições dos áudios, as entrevistas foram devolvidas aos participantes, para que pudessem lê-las e proceder às alterações que julgassem necessárias. As redações também lhes foram remetidas, com sinais nos textos que indicavam pequenas dúvidas a serem dirimidas. As negociações com os participantes a respeito das alterações sugeridas foram tranquilas, e o pesquisador acatou todas as mudanças solicitadas.

No processo de análise textual discursiva proposto por Moraes (2003), emergiram as seguintes categorias, a partir dos dados coletados: "Dificuldades"; "Auxílio de terceiros"; "Qualidade da educação básica cursada"; "Tomada de consciência e vontade". As três primeiras categorias serão discutidas brevemente; a última, considerada a principal, será debatida com maior ênfase à luz das ideias vygotskianas. 


\section{Achados da pesquisa}

Em termos das dificuldades encontradas, foram apontados diferentes aspectos. Primeiramente, os participantes chamaram a atenção para os problemas relativos ao processo de seleção para a entrada na universidade, dentre os quais: provas não-impressas em braille e realização dos exames com auxílio de um ledor que, não raro, era mal preparado para a tarefa. A participante SF1 assim expõe a sua percepção sobre o referido processo:

[...] o vestibular foi um problema: os professores leram a prova para mim. Eu não gosto de fazer provas orais. Há muitos mitos a respeito dos cegos, dentre os quais: o mito (do qual discordo veementemente, até mesmo porque eu não tenho esse dote, esse dom, ou não sei como pode ser chamado) de ter facilidade de memória; de se ter audição desenvolvidíssima etc. Eu não tenho nada disso e nem quero ter ${ }^{7}$.

Tais dificuldades denunciam problemas de organização das instituições de ensino superior, especialmente a ausência de políticas efetivas de inclusão que abarquem a reestruturação e avaliação do vestibular e do Exame Nacional do Ensino Médio (Enem), no que concerne à participação dos

deficientes. É possível analisar, não apenas as questões instrumentais do processo seletivo, mas também a experiência, vivenciada e denunciada pela participante, de ser vista a partir de ideias estereotipadas sobre as pessoas com cegueira. Todos os sujeitos salientaram que, passado o processo de seleção, também se depararam com a falta de preparo das universidades para recebê-los e dos professores para o trabalho pedagógico a eles dirigido, discutidos na sequência.

Ao tecerem comentários acerca de suas vivências na educação superior, os participantes diziam, como se estivessem falando em uníssono: "a universidade não estava preparada para a inclusão". Essa fala foi acompanhada pelo relato das dificuldades pelas quais passaram ao realizar sua graduação e evidenciam o seu sentimento em relação ao acolhimento e ao preparo pedagógico e estrutural das instituições. Rocha e Miranda (2009) também denunciam essa falta de preparo, indicando que, apesar de todas as campanhas pela inclusão e da legislação vigente, ainda é preciso que as instituições de ensino superior promovam práticas que beneficiem os processos de ensino e de aprendizagem do deficiente.

Em relação à falta de preparo de alguns docentes, os entrevistados relataram que, segundo suas percepções, apenas certos professores apresentavam condições para receber o aluno cego na universidade. Os sujeitos afirmaram que as dificuldades na relação com os docentes foram, algumas vezes, bastante desgastantes e também estiveram entre os fatores que tornaram complicada sua inclusão 
no ensino superior. As dificuldades interpessoais descritas, as quais expressam, também, os motivos que levaram os participantes a acreditarem que somente alguns docentes apresentavam condições para o ensino de cegos, foram: preconceito, insegurança por parte de certos docentes na relação com os cegos e sentimentos de pena dirigidos a eles.

O preconceito do professor para com o estudante cego, por exemplo, apareceu em diferentes momentos e de distintas maneiras: em comentários negativos (proferidos em reuniões entre professores e estudantes, segundo a redação de SM4, 2011b); em práticas pedagógicas consideradas pelos sujeitos como incoerentes (tais como querer que o cego escrevesse a prova com caneta esferográfica, conforme relata SM5, na entrevista) e em conselhos (para trocar de curso ou parar de estudar, de acordo com SM2, 2011b, em sua redação). O relato a seguir mostra um exemplo literal a respeito desse tipo de comportamento docente:

Há também comentários negativos que alguns professores faziam, tipo: "como é que você vai fazer para saber isso?"; "como é que você vai aplicar isso?”. Então, são preconceitos velados porque você não precisa adiantar nada para mim. A hora que chegar, no momento, eu faço. Então, coisas que nem eles tinham me ensinado e queriam que eu respondesse; como é que eu iria aplicar. Então, com certeza, era preconceito. $(\mathrm{SM} 3)^{8}$.

Quanto à insegurança dos docentes, frente à presença do deficiente, o depoimento da entrevista de SM1 foi claro: "existe insegurança do docente para lidar com o aluno deficiente. Eu noto isso, a rigidez de alguns professores ao tentar estabelecer contato com o cego". Essa rigidez foi explicada pelo participante por sua percepção da tentativa constante do professor de evitar o aluno deficiente, não o procurando para conversar ou debater sobre os assuntos referentes à aula, ou mesmo, quando procurado pelo sujeito, em dar desculpas para não ter que encará-lo. O entrevistado acredita que tais atitudes podem, inclusive, interferir no seu processo de aprendizagem, já que o professor evita (ou não consegue) conversar com o estudante sobre os conteúdos do componente curricular.

Ainda que atitudes preconceituosas ou de insegurança fossem consideradas como prejudiciais, alguns sujeitos relataram que, entre as piores dificuldades interpessoais, por parte dos professores, estavam aquelas que envolviam sentimentos de comiseração, tal como se observa no relato de SM3:

Uma das piores situações que o professor pode provocar para o aluno que não enxerga é, justamente, não provocar nenhuma situação de ensino, "passar a mão por cima”, ter pena do aluno, não exigir dele o mesmo que exige dos demais, atribuir-lhe a maior nota sem merecimento, seja por comodismo, seja por pena, ou por incompetência própria. (SM3, informação oral). 
Auxiliando no entendimento dos comportamentos docentes acima mencionados, Mazzoni e Torres (2005), e Masini e Bazon (2005) salientam o escasso conhecimento, por parte de alguns professores, sobre as necessidades específicas das pessoas com deficiência visual. Os pesquisadores argumentam que essa situação contribui para a formação de falsos conceitos sobre esse grupo de pessoas e gera o desenvolvimento de atitudes e comportamentos discriminatórios em relação a elas.

Todos os participantes salientaram, entretanto, que as dificuldades interpessoais na relação com os docentes não eram generalizadas, pois houve professores que apoiaram os deficientes, em diferentes momentos de seu curso superior (tal como se verá na discussão acerca da categoria "auxílio de terceiros").

A falta de instrumental tecnológico e material adaptado constituiu-se em mais uma das dificuldades apontadas. Os participantes afirmaram que teria sido fundamental que a universidade lhes oferecesse gravador de mão, impressora braille e notebook, o que não ocorreu. Além disso, apontaram a necessidade de cada estudante cego ser consultado sobre o formato no qual preferia receber o material para seus estudos (esquemas de aulas, livros, textos de aporte, artigos científicos): em braille, audiolivro ou formato digital.

Muitas das dificuldades encontradas pelos cegos no ambiente universitário também estão ligadas, evidentemente, à falta de adequação física desses espaços para aqueles que não enxergam. Há diferentes obstáculos arquitetônicos que impedem o deslocamento seguro do cego pelas dependências das instituições universitárias. Os resultados das investigações de Mazzoni e Torres (2005), Masini e Bazon (2005) e Delpino (2004) indicam alguns dos principais entraves arquitetônicos para esse deslocamento: desníveis nas calçadas, objetos móveis e imóveis colocados em locais inapropriados (bancos, motocicletas etc.), desrespeito às faixas de pedestres por motoristas de automóveis e ciclistas dentro do campus, entre outros.

Constatou-se, por meio dos depoimentos dos sujeitos cegos, que os fatores recém-discutidos tornaram difícil seu caminho pelo ensino superior. Entretanto, eles conseguiram enfrentá-los e superálos, atingindo sua meta de obter um diploma de curso superior. Nesse caminho, receberam auxílio de pessoas de fora da universidade (categoria auxílio de terceiros), embora tenha sido também mencionada a ajuda de alguns professores.

Os participantes SM1, SM2, SM4, SM6, SF2 e SF3 citaram suas mães como as principais auxiliares durante seu percurso acadêmico. Segundo SF3, "minha mãe me ditava os livros, lia os livros. Minha mãe praticamente se formou comigo"9. A ajuda proveniente desse familiar consistiu, por 
exemplo: na procura, nas bibliotecas universitárias, por materiais teóricos impressos (não disponibilizados em meio acessível) que complementassem os estudos realizados em aula; na leitura desse material para o estudante cego, em voz alta; na busca por instituições não governamentais que pudessem imprimir alguns dos textos, que deveriam ser trabalhados nos componentes curriculares, em formato braille. SM4, em sua redação, incluiu o apoio dos amigos, apesar de não explicar como isso aconteceu: "o apoio da família e dos amigos me fez persistir em minha caminhada durante a graduação".

Quanto à ajuda de alguns professores, os participantes (SM2, SM4, SF1, SF2 e SF3) relataram que foram apoiados em espaços e momentos que excediam a sala de aula. Ações como mediar o aprendizado dos conteúdos fora do ambiente universitário e procurar formas de transcrever o material impresso para o formato braille e entregá-lo ao estudante (mesmo que a instituição universitária não provesse as condições para isso), foram citadas para exemplificar a importância desse tipo de auxílio. A participante SF1(2011b), em sua redação, assim se expressou:

Uma menção especial a uma professora, a qual teve importante destaque nos meus estudos e na minha vida. Ela sempre me deu apoio, desde o primeiro contato que tivemos, fosse me enviando material por e-mail, disquete, cd ou outros meios, fosse numa conversa amiga, ajudando-me a vislumbrar as possibilidades para que eu pudesse ter o meu direito de qualidade nos estudos, como os outros colegas com visão poderiam ter. Esta professora representa para mim uma pessoa muito querida e diferenciada em minha vida.

Outro fator apontado pelos cegos como favorável à conclusão do ensino superior foi a qualidade da educação básica cursada. Alguns deles afirmaram que o período de escolarização anterior à sua entrada na universidade influenciou sua trajetória pela educação superior. Estes sujeitos (SM1, SM2, SM3, SF2, SF3), durante as entrevistas, sugeriram que, quando a educação básica, efetivamente, promove aprendizagem, então o ingresso na educação superior é facilitado.

Os dados coletados não permitem que se explique o que os sujeitos quiseram dizer quando utilizaram a palavra aprendizagem, mas se pode pensar que estivessem se referindo à compreensão dos conteúdos, que adquiriram sentido e foram integrados em rede com seus conhecimentos prévios, permitindo seu emprego adequado. Com base nas ideias de Vigotski (2001), esse tipo de aprendizagem pode ser considerado como útil, diferindo da memorização mecânica, que tende a não ser significava e resulta em fácil esquecimento e limitada possibilidade de utilização. Segundo a concepção teórica desenvolvida por Vigotski (1998), as "boas aprendizagens" ocorrem quando o processo de ensino é voltado à zona de desenvolvimento proximal do estudante, isto é, são efetivadas com auxílio de alguém 
mais capaz, em situações compartilhadas. Essa aprendizagem pode ocorrer por meio da imitação (que, para o autor, é diferente da cópia, envolvendo atividade e compreensão de quem imita), mas difere da simples incorporação de informações, por parte do aprendiz.

Apesar do auxílio que receberam de outras pessoas, dos professores e dos familiares, apesar do ensino de boa qualidade que julgam ter tido, anteriormente ao ingresso no ensino superior, os depoimentos dos sujeitos indicaram que não teriam conseguido concluir essa etapa da escolarização se não fosse a tomada de consciência sobre a necessidade de um diploma de nível superior para atingir um nível de vida satisfatório. A tomada de consciência da importância de realizar alguma tarefa, entretanto, não leva, necessariamente, uma pessoa a realizá-la. Em adição à consciência, é necessária a vontade para que a tarefa seja realizada. Mas como seria gerada essa vontade?

A seguir, na categoria emergente tomada de consciência e vontade, discute-se esta questão, com base na teoria vygotskiana, haja vista os sujeitos cegos considerarem que consciência e vontade foram os elementos fundamentais para a conclusão do curso superior, apesar dos outros fatores, antes mencionados, terem também contribuído para isso.

\section{A tomada de consciência e a vontade a partir de Vygotski}

Para Vygotski (1982), o ato volitivo é aquele que, em certas condições, permite a ação livre. Este autor (VIGOTSKI, 1984) entende que a vontade é a responsável pelo domínio de nossa conduta. O ser humano difere dos animais por sua capacidade de escolha e esta é a forma mais típica de conduta volitiva (VYGOTSKI, 1995). Mas a vontade não é algo inerente ao ser humano ou derivada de uma força espiritual, desvinculada de suas vivências sociais concretas. Segundo Rey (2009), Vygotski considera que os atos motivados são sínteses subjetivas de tais vivências.

Frequentemente, as pessoas defrontam-se com a necessidade de escolher cursos de ação em suas vidas. Quando tais escolhas envolvem decisões e comportamentos conflitantes (no caso dos sujeitos desta pesquisa, enfrentar as dificuldades envolvidas em frequentar um curso superior ou desistir do curso, devido a tais dificuldades) pode-se criar um impasse, que necessita ser resolvido. Nesses casos, como explica Vigotski (1984), as pessoas podem apoiar-se em um motivo auxiliar externo (a sorte lançada em um jogo de dados ou uma causa considerada importante, por exemplo), por elas mesmas estabelecido, para tomar suas decisões. Tomada a decisão, gera-se a vontade de agir para levá-la a cabo. 
Os textos de Vygotski relacionados ao estudo da vontade destacam, primeiramente, a relação desta com a consciência, ou seja, a percepção dos conteúdos da própria mente (VIGOTSKI, 2001), possibilitada pelo uso de signos, especialmente da linguagem. Os signos permitem que se representem, mentalmente, os estímulos provenientes do meio. Libertamo-nos de nossas respostas impulsivas, controlando, conscientemente, nosso comportamento. A vontade é, então, gerada pela consciência de uma necessidade. Entretanto, para que o controle ocorra, necessitamos mais do que consciência, pois ela sozinha não é capaz de direcionar nossas funções psicológicas superiores, a vontade aí incluída. Essas funções, especialmente a consciência (mas também a atenção e a memória), estão estreitamente ligadas às emoções - ou afecções provocadas por objetos, pessoas ou imagens de nosso entorno. As emoções desempenham papel orientador e direcionador do comportamento humano (AIDMAN; LEONTIEV, 1991; TOASSA, 2006), ou seja, quando afetados por um estímulo auxiliar, podemos direcionar nosso comportamento em direção a tal estímulo. Segundo explicava Vigotski (2001, p. 479, grifo do autor):

O próprio pensamento não nasce de outro pensamento mas do campo da nossa consciência que o motiva, que abrange os nossos pendores e necessidades, os nossos interesses e motivações, os nossos afetos e emoções. Por trás do pensamento existe uma tendência afetiva e volitiva. Só ela pode dar a resposta ao último porquê na análise do pensamento.

Pode-se pensar que os sujeitos desta pesquisa tenham insistido em continuar seus estudos, apesar das dificuldades enfrentadas, justamente porque tomaram consciência da importância desse curso de ação para sua vida (estímulo auxiliar). Os motivos auxiliares não forçam as pessoas a agir de determinado modo, mas ajudam no processo de tomada de decisão sobre o curso da ação a ser realizada e, uma vez estabelecidos, passam a sempre mediar aquele tipo de ação (VIGOTSKI, 2001).

Um dos depoimentos que ilustra o funcionamento do estímulo auxiliar para a escolha por manter-se no curso superior e concluí-lo, ainda que enfrentando dificuldades, foi o do sujeito SM5 (entrevista). Ele relatou que considerava grande a diferença cultural entre si e a namorada, pensando que isso poderia comprometer o futuro casamento: na época, sua companheira estava na faculdade e ele recém concluíra o ensino médio. Esse fato foi fundamental para que fosse nele gerada a vontade de lutar para entrar para a faculdade e nela permanecer: "pois eu conhecia casais que não davam certo pela diferença do grau cultural, em que ela tinha curso superior e ele não. Dizem que se o amor é grande, tem que superar. Mas penso que não é só isso[...]"10. Nesse depoimento, o participante SM5 mostra que a tomada de consciência sobre a diferença de nível educacional entre ele e sua noiva foi 
eivada de afeto, engendrando uma vontade de lutar contra as possíveis dificuldades para ingressar e se manter no curso superior, até sua conclusão.

O sujeito SM5 teve, também, outra experiência que gerou a vontade de lutar para concluir a faculdade: o nascimento do filho. O depoimento que segue ilustra com clareza o quanto esse fato afetou sua vida:

No segundo semestre de faculdade, nasceu meu primeiro filho, outro fator preponderante para eu continuar a luta, pois, além de dar exemplo, queria que ele tivesse orgulho de seu pai, assim como eu tinha do meu. A responsabilidade aumentava em todos os sentidos. Mais do que nunca, eu precisava ser alguém e, para isso, teria que superar todas as barreiras que encontrasse pelo caminho.

A decisão de enfrentar os desafios implicados no curso superior também parece ter sido fruto da tomada de consciência eivada de afetos nos outros sujeitos da pesquisa. SM3, SF1 e SF2, por exemplo, foram movidos pela percepção de que o diploma de curso superior serviria para melhorar suas condições financeiras. Os relatos a seguir exemplificam as compreensões dos sujeitos: SM3 disse que "na verdade, vem na esperança de vida melhor. Quando eu fiz a Fisioterapia, foi para melhorar a minha condição profissional e financeira"; SF1, por sua vez, declarou o seguinte:

Acredito que a minha determinação de fazer a faculdade também se deve a minha dificuldade financeira. Porque os meus pais eram pobres, sempre foram. Eu achava que tinha que melhorar da vida. O que aconteceu é que foi tudo um "auê": eu fiquei com aquilo na minha cabeça. Eu ouvia aquilo da pobreza desde pequena e eu tinha determinação. Eu tinha todos os motivos para não fazer faculdade. Então eu acredito que estou no grupo, também, daquelas pessoas que têm dificuldades financeiras. Eu acho que participo também do grupo da mobilidade social, pois eu mudei a minha condição social. Realmente, eu mudei por causa dos meus esforços, dos meus estudos, da minha dedicação ${ }^{11}$.

SF2 também comentou: "Não desisti pelo sonho que tinha em cursar História. Tinha que ter condições financeiras de me sustentar. Não ia ficar na 'barra da saia da mãe', a vida toda"12.

Para SM2, SM3, SM4 e Bertoldo, a ideia de que o diploma de nível superior permitiria ingresso mais qualificado no mundo do trabalho parece ter sido o motivo auxiliar para gerar a vontade de se manter estudando. Nas palavras de SM2, "minha formação profissional foi para me habilitar para o mercado de trabalho"13. Já SM3, argumentou: "Fiz faculdade para encontrar um trabalho com mais facilidade, pelo menos eu achava isso naquela época [...] apostar no estudo, saber que com um currículo melhor você tem mais possibilidades de um bom emprego [...]”. 
SM4 (2011b) escreveu em sua redação: "o desejo de ter uma profissão e conseguir uma independência econômica foram fundamentais para eu continuar a graduação, não desistir diante das dificuldades que se apresentaram". Durante o procedimento de coleta de dados a respeito da biografia de Bertoldo, sua irmã, na entrevista, salientou: "Creio que ele já nasceu com essa ideia de que tinha essa missão de batalhar para que ele fosse uma pessoa autossuficiente, um cidadão que podia ser como qualquer outra pessoa, capaz de exercer uma profissão. Era essa a missão dele"14.

$\mathrm{Na}$ contramão dos problemas existentes para qualquer estudante brasileiro, os cegos participantes deste estudo tomaram a decisão de participar do processo seletivo para a entrada em uma universidade, permaneceram nela e concluíram o curso superior, agindo com a liberdade que é peculiar ao ser humano adulto.

\section{Considerações finais}

Acredita-se que a compreensão do comportamento dos sujeitos da pesquisa, quanto à conclusão do ensino superior foi adequadamente viabilizada pela Psicologia Histórico-Cultural de Vygotski. Esta permitiu a pressuposição de que ocorreu nos sujeitos, por detrás dessa conquista, um processo de tomada de consciência, eivado de afeto, sobre suas necessidades e a consequente vontade de lutar contra as adversidades e superá-las, até atingir os objetivos desejados. Imaginar a parte imersa do iceberg implica considerar que essa parte, que é a maior, é responsável pela sua sustentação e estabilidade. Contudo, é importante frisar que as partes imersa e emersa integram um todo, único.

O fato de considerar a importância da tomada de consciência e da vontade dos sujeitos para a conclusão da educação superior, portanto, não pode ser visto como desculpa para os docentes e as instituições ficarem inertes, até porque, como vimos anteriormente, a vontade não é algo que nasce com o indivíduo, mas é forjada em suas vivências na sociedade. Não se exime, para o sucesso na escolarização dos cegos, o papel dos gestores e professores, que respondem pela inclusão educacional e que podem também ser criadores de estímulos auxiliares para guiar o comportamento de luta pela superação das dificuldades. Os professores podem, por exemplo, incentivar os alunos cegos a concluir a educação superior alertando-os sobre a importância dessa conquista para o seu futuro profissional e pessoal. $\mathrm{O}$ incentivo do professor pode gerar no seu aluno a confiança e a possibilidade da vontade, se conseguir afetar os cegos. 
Esta sugestão pode ser estendida às famílias dos cegos, parte citada como importante para a conclusão da educação superior. Muitas dessas famílias tendem a superprotegê-los, quando deveriam auxiliá-los na tomada de consciência sobre a importância da educação superior e da capacidade que têm para cursá-la, superando a deficiência, tal como Vygotski (1997) salienta em sua Defectologia.

Ao finalizar, é importante frisar que se espera que os resultados desta investigação possam ser objeto de debate, causa de inquietações e fonte de informações àqueles que os lerão, seja com os olhos, seja com a ponta dos dedos.

\section{Notas}

${ }^{1} \mathrm{O}$ termo cego (cegueira) utilizado neste estudo está de acordo com o manifesto pela legislação brasileira (BRASIL, 2004), que apresenta uma diferenciação entre cegueira e baixa visão, da seguinte maneira: cegueira, na qual a acuidade visual é igual ou menor que 0,05 no melhor olho, com a melhor correção óptica; baixa visão, que significa acuidade visual entre 0,3 e 0,05 no melhor olho, com a melhor correção óptica; os casos nos quais a somatória da medida do campo visual em ambos os olhos for igual ou menor que $60^{\circ}$; ou a ocorrência simultânea de quaisquer das condições anteriores.

${ }^{2}$ Os resumos técnicos do penúltimo e do último censo da educação superior, respectivamente do ano de 2010 (BRASIL, 2012) e 2011 (BRASIL, 2013a) não especificaram dados correspondentes à matrícula de cegos, nesta etapa da escolarização.

${ }^{3}$ Apenas a partir da segunda metade do século XX foi que cegos conquistaram a possibilidade de realizar a educação superior no território nacional. No estado do Rio Grande do Sul, por exemplo, concluiu a educação superior, na Pontifícia Universidade Católica do Rio Grande do Sul (PUCRS), no ano de 1957, Walkírio Ughini Bertoldo, este considerado o primeiro advogado cego formado no Brasil (SELAU e DAMIANI, 2014). Em 1953, quando Bertoldo procurou a PUCRS para prestar exame vestibular, esse direito lhe foi negado, justamente pelo fato de ser ele cego. Foi apenas quando apresentou para esta instituição uma carta de aceite da faculdade de Direito da Universidad de Buenos Aires, conseguiu "provar que era, sim, possível um cego cursar o ensino superior" (SELAU e DAMIANI, 2014, p. 422).

${ }^{4}$ Utilizar-se-á esta grafia do nome do autor bielorrusso, a não ser quando se fizerem citações de edições que empregaram outras formas de escrita.

${ }^{5}$ Todas as normas referentes a ética em pesquisa com seres humanos foram devidamente seguidas, durante toda a investigação, e autorizadas pela instituição na qual se desenvolveu a tese de doutorado em apresentação.

${ }^{6}$ Com consentimento da família para divulgação das informações pessoais.

${ }^{7}$ Entrevista concedida por SM 1. Entrevista I. [2 $2^{\circ}$ semestres de 2010 e 2011]. Entrevistador: Bento Belau. Pelotas, 2011.1 arquivo .mp3 em posse do autor. Os roteiros da entrevista encontram-se nos Apêndices B e C de Belau (2013), referenciado neste artigo.

${ }^{8}$ Entrevista concedida por SM 3. Entrevista IV. [2 ${ }^{\circ}$ semestre de 2010 e 2011]. Entrevistador: Bento Belau. Pelotas, 2011.1 arquivo .mp3 em posse do autor. Os roteiros da entrevista encontram-se nos Apêndices B e C de Belau (2013), referenciado neste artigo.

${ }^{9}$ Entrevista cedida por SF 3. Entrevista VII. [2º semestre de 2011]. Entrevistador: Bento Belau. Pelotas, 2011.

1 arquivo .mp3 em posse do autor. O roteiro da entrevista encontra-se no Apêndice C de Belau (2013), referenciado neste artigo.

${ }^{10}$ Entrevista cedida por SM 5. Entrevista IX. [2 ${ }^{\circ}$ semestre de 2011]. Entrevistador: Bento Belau. Pelotas, 2011a. 
1 arquivo .mp3 em posse do autor. O roteiro da entrevista encontra-se no Apêndice C de Belau (2013), referenciado neste artigo.

${ }^{11}$ SF 1. Entrevista III. [2 ${ }^{\circ}$ semestre de 2010 e 2011]. Entrevistador: Bento Belau. Pelotas, 2011a.

1 arquivo .mp3 em posse do autor. Os roteiros da entrevista encontram-se nos Apêndices B e C de Belau (2013), referenciado neste artigo.

${ }^{12}$ SF 2. Entrevista V. [2 $2^{\circ}$ semestre de 2011]. Entrevistador: Bento Belau. Pelotas, 2011a.

1 arquivo .mp3 em posse do autor. O roteiro da entrevista encontra-se no Apêndice C de Belau (2013), referenciado neste artigo.

${ }^{13}$ SM 2. Entrevista II. [2 $2^{\circ}$ semestre de 2010 e 2011]. Entrevistador: Bento Belau. Pelotas, 2011a.

1 arquivo .mp3 em posse do autor. Os roteiros da entrevista encontram-se nos Apêndices B e C de Belau (2013), referenciado neste artigo.

${ }^{14}$ Entrevista cedida por Léa Amaral. Entrevista X. [2º semestre de 2011]. Entrevistador: Bento Belau. Pelotas, 2011a. 1 arquivo .mp3 em posse do autor. O roteiro da entrevista encontra-se no Apêndice F de Belau (2013), referenciado neste artigo.

\section{REFERÊNCIAS}

AIDMAN, E. V., LEONTIEV, D. A. From being motivated to motivating oneself: a vygotskian perspective. Studies in Soviet Thought, Fribourg, 42, n. 2, p. 137-15, 1991. Disponível em: $<$ http://link.springer.com/article/10.1007\%2FBF00818841>. Acesso em: 16 ago. 2013.

AMARAL, L. Entrevista X. [2º semestre de 2011]. Entrevistador: Bento Belau. Pelotas, 2011a. 1 arquivo .mp3 em posse do autor. O roteiro da entrevista encontra-se no Apêndice F de Belau (2013), referenciado neste artigo.

BAUER, M. W.; GASKELL, G. Pesquisa qualitativa com texto, imagem e som: um manual prático. Petrópolis: Vozes, 2002.

BAZON, F. V. M. As mútuas influências, família-escola, na inclusão escolar de crianças com deficiência visual. 2009. 574 f. Tese (Doutorado em Educação) - Universidade de São Paulo, São Paulo, 2009.

BOGDAN, R. C.; BIKLEN, S. K. Investigação qualitativa em educação: uma introdução à teoria e aos métodos. Porto: Porto Editora, 1994.

BRASIL. Decreto N. ${ }^{\circ}$ 5.296, de 2 de dezembro de 2004. Regulamenta as Leis n. ${ }^{\circ} 10.048$, de 8 de novembro de 2000, que dá prioridade de atendimento às pessoas que especifica, e n. ${ }^{\circ} 10.098$, de 19 de dezembro de 2000, que estabelece normas gerais e critérios básicos para a promoção da acessibilidade das pessoas portadoras de deficiência ou com mobilidade reduzida, e dá outras providências. Diário Oficial da União, Brasília, DF, 3 dez. 2004. Disponível em: <http://www.planalto.gov.br/ccivil_03/_ato2004-2006/2004/decreto/D5296.htm>. Acesso em: 20 abr. 2011.

BRASIL. Ministério da Educação. Política Nacional de Educação Especial na Perspectiva da Educação Inclusiva. Brasília: MEC/Seesp, 2008. 
BRASIL. Ministério da Educação. Instituto Nacional de Estudos e Pesquisas Educacionais Anísio Teixeira. Censo da Educação Superior: 2009. Brasília: INEP, 2010.

BRASIL. Ministério da Educação. Instituto Nacional de Estudos e Pesquisas Educacionais Anísio Teixeira. Censo da Educação Superior: 2010. Brasília: INEP, 2012.

BRASIL. Ministério da Educação. Instituto Nacional de Estudos e Pesquisas Educacionais Anísio Teixeira. Censo da educação superior: 2011. Brasília: INEP, 2013a.

BRASIL. Ministério da Educação. Secretaria de Educação Continuada, Alfabetização, Diversidade e Inclusão/Secretaria de Educação Superior. Documento Orientador

Programa Incluir: acessibilidade na Educação Superior. 2013. Brasília: SECADI/SESu, 2013 b.

Disponível em:

$<$ http://portal.mec.gov.br/index.php?option=com_docman\&view=download\&alias=12737-documentoorientador-programa-incluir-pdf\&category_slug=marco-2013-pdf\&Itemid=30192>. Acesso em: 28 mar. 2016.

BRASIL. Decreto No 7.611, de 17 de novembro de 2011. Dispõe sobre a educação especial, o atendimento educacional especializado e dá outras providências. Diário Oficial da União, Brasília, DF, 18 nov. 2011. Disponível em: <http://www.planalto.gov.br/ccivil_03/_ato20112014/2011/decreto/d7611.htm>. Acesso em: 23 set. 2015.

BRASIL. Lei No 13.146, de 6 de julho de 2015. Institui a Lei Brasileira de Inclusão da Pessoa com Deficiência (Estatuto da Pessoa com Deficiência). Diário Oficial da União, Brasília, DF, 7 jul. 2015. Disponível em: <http://www.planalto.gov.br/ccivil_03/_Ato2015-2018/2015/Lei/L13146.htm>. Acesso em: 23 set. 2015.

CAIADO, K. R. M. Aluno deficiente visual na escola: lembranças e depoimentos. Campinas, SP: Autores Associados, 2003.

CAIADO, K. R. M.; GARCIA, R. M. C. Apresentação. Cadernos CEDES, Campinas, v. 28, n. 75, p. 139-145, 2008. Disponível em: <http://www.cedes.unicamp.br >. Acesso em: 15 maio 2010.

DELPINO, M. Facilidades e dificuldades encontradas pelos alunos com deficiência visual no curso superior. 2004. 141 f. Dissertação (Mestrado em Distúrbios do Desenvolvimento) - Universidade Presbiteriana Mackenzie, São Paulo, 2004.

FREITAS, M. T. A. O pensamento de Vygotsky nas reuniões da ANPEd (1998-2003). Educação \& Pesquisa, São Paulo, v. 30, n. 1, p. 109-138, 2004.

LÜDKE, M.; ANDRÉ, M. E. D. Pesquisa em educação: abordagens qualitativas. São Paulo: EPU, 1986.

MASINI, E. F. S.; BAZON, F. V. M. A inclusão de estudantes com deficiência, no ensino superior. In: REUNIÃO ANUAL DA ANPED, 28, 2005, Caxambu. Anais... Caxambu, 2005. Disponível em: <http://www.anped.org.br/reunioes/28/inicio.htm>. Acesso em: 22 fev. 2011. 
MAZZONI, A. A.; TORRES, E. F. A percepção dos alunos com deficiência visual acerca das barreiras existentes no ambiente universitário e seu entorno. Revista Benjamin Constant, Rio de Janeiro, v. 30, p. $1-12,2005$.

MORAES, R. Uma tempestade de luz: a compreensão possibilitada pela análise textual discursiva. Ciência \& Educação, Bauru, SP, v. 9, n. 2, p. 191-211, 2003.

OKA, C. M.; NASSIF, M. C. M. Recursos escolares para o aluno com cegueira. In: SAMPAIO, M. W. et al. Baixa visão e cegueira: os caminhos para a reabilitação, a educação e a inclusão. Rio de Janeiro: Guanabara Koogan, 2010. p. 389-414.

OLIVEIRA, B. M. Construção de saberes e significações imaginárias na trajetória de vida de uma alfabetizadora cega. 2008. 118 f. Dissertação (Mestrado em Educação) - Universidade Federal de Santa Maria, Santa Maria, 2008.

OLIVEIRA, L. C. P. Trajetórias escolares de pessoas com deficiência visual: da Educação Básica ao Ensino Superior. 2007. 158 f. Dissertação (Mestrado em Educação) - Pontifícia Universidade Católica de Campinas, Campinas, SP, 2007.

OLLAIK, L. G.; ZILLER, H. M. Concepções de validade em pesquisas qualitativas. Educação e Pesquisa, São Paulo, v. 38, n. 1, p. 229-241, 2012.

PUJADAS MUÑOZ, J. J. El método biográfico: el uso de las historias de vida en ciencias sociales. 2. ed. Madrid: Centro de Investigaciones Sociológicas, 2002.

RAPOSO, P. N. O impacto do sistema de apoio da Universidade de Brasília na aprendizagem de universitários com deficiência visual. 2006. 164 f. Dissertação (Mestrado em Educação) Universidade de Brasília, Brasília, DF, 2006.

REY, F. G. La significación de Vygotski para la consideración de lo afectivo en la educación: las bases para la cuestión de la subjetividad. Revista Electrónica Actualidades Investigativas en Educación, San José, v. 9, n. especial, p. 1-24, 2009. Disponível em: <http://www.redalyc.org/pdf/447/44713052003.pdf >. Acesso em: 16 ago. 2013.

ROCHA; T. B.; MIRANDA, T. G. Acesso e permanência do aluno com deficiência na instituição de ensino superior. Revista de Educação Especial, Santa Maria, RS, v. 22, n. 34, p. 197-212, 2009.

RODRIGUES, D. A inclusão na universidade: limites e possibilidades da construção de uma universidade inclusiva. Revista de Educação Especial, Santa Maria, RS, n. 23, 2004. Disponível em: <http://coralx.ufsm.br/revce/ceesp/2004/01/a1.htm>. Acesso em: 12 jan. 2012.

SELAU, B. Fatores associados à conclusão da educação superior por cegos: um estudo a partir de L. S. Vygotski. 2013. 287f. Tese (Doutorado em Educação) - Universidade Federal de Pelotas, Pelotas, RS, 2013.

SELAU, B.; DAMIANI, M. F. Quando não se falava em inclusão: a história de vida do primeiro advogado cego formado no Brasil. Revista Educação Especial, Santa Maria, RS, v. 27, n. 49, p. 417- 
430, 2014. Disponível em: <http://cascavel.ufsm.br/revistas/ojs2.2.2/index.php/educacaoespecial/article/view/9633/pdf>. Acesso em: 15 dez. 2015.

SELAU, B.; HAMMES, L. J. Inclusão de cegos na educação superior: algumas estratégias para superação de obstáculos. In: ANPED SUL, 10, Florianópolis, 2014. Anais... Florianópolis: ANPEd, 2014. Disponível em: <http://xanpedsul.faed.udesc.br/arq_pdf/148-0.pdf>. Acesso em: 20 dez. 2015.

SIQUEIRA, I. M.; SANTANA, C. S. Propostas de acessibilidade para a inclusão de pessoas com deficiências no Ensino Superior. Revista Brasileira de Educação Especial, Marília, v. 16, n. 1, p. 127 136, 2010.

TOASSA, G. Conceito de consciência em Vigotski. Psicologia USP, São Paulo, v. 17, n. 2, p. 59-83, 2006.

UM fato em foco. O Cruzeiro, Rio de Janeiro, 11 jan. 1958.

VIGOTSKI, L. S. A formação social da mente. 6. ed. São Paulo: Martins Fontes, 1998.

VIGOTSKI, L. S. A construção do pensamento e da linguagem. São Paulo: Martins Fontes, 2001.

VIGOTSKI, L. S. Paidología del adolescente. In: VIGOTSKI, L. S. Obras escogidas. Moscú: Pedagóguika, 1984. v. 4. p. 9-247.

VYGOTSKI, L. S. Acerca de los procesos compensatorios en el desarrollo del niño mentalmente retrasado. In: VIGOTSKI, L. S. Obras escogidas: fundamentos de defectología. Madrid: Visor, 1997. v. 5. p. 131-152.

VYGOTSKI, L. S. Historia del desarrollo de las funciones psíquicas superiores. In: VIGOTSKI, L. S. Obras escogidas: problemas del desarrollo de la psique. Madrid: Visor, 1995. v. 3. p. 11-340.

VIGOTSKI, L. S. Obras escogidas. Moscú: Pedagóguika, 1982. 


\section{The conclusion of higher education by the blind and the psychology of Vygotski: the tip of the iceberg}

\begin{abstract}
This paper aims to present the factors related to the conclusion of higher education, by a group of blind students, from their own point of view. Case studies with nine subjects were made, as the data were collected through narrative inquiry and document analysis, and also submitted to a process of discourse analysis. The Cultural- Historical Psychology of Vygotski was the framework that based the research. The findings highlight factors that complicate the conclusion of higher education as the selection process, which ignores the needs of the blind; the lack of preparedness by the institutions to serve the disabled; prejudice by the teachers. At the same time, they indicate factors that favored this conclusion - like the help to the blind by professors and family, the awareness of the importance of university education for their future lives generating desire to achieve it.
\end{abstract}

Keywords: Higher Education. Blindness. CulturalHistorical Psychology.

\section{La conclusión de la educación superior por ciegos y la psicología de Vygotski: la punta del iceberg}

\section{Resumen}

Este trabajo tiene como objetivo presentar los factores relacionados a la conclusión de la educación superior, realizada por algunos estudiantes ciegos, a partir de sus própios puntos de vista. Se realizaron estudios de casos con nueve sujetos, siendo los datos colectados através de entrevistas narrativas, análisis de documentos y submetidos a un proceso de análisis del discurso textual. La perspectiva teórica de la investigación fue la Psicología Histórico-Cultural de Vygotski. Los resultados apuntan factores que dificultan la finalización de la educación superior - como el proceso de selección que ignora las necesidades de los ciegos; la falta de condiciones de las instituciones para atender a los discapacitados; los prejuicios de los docentes. Al mismo tiempo, también existieron factores que favorecieron esa conclusión - como el auxilio a los ciegos de parte de docentes y familiares, la toma de conciencia sobre la importancia de la formación universitária para sus vidas futuras generando la voluntad para alcanzarla.

Palabras claves: Educación Superior. Ceguera. Psicología Historico-Cultural.

Enviado em: 20/8/2014

Aprovado em: 8/3/2016
Magda Floriana Damiani
E-mail: flodamiani@gmail.com

Magda Floriana Damiani
E-mail: flodamiani@gmail.com

Bento Selau

E-mail: bentoselau@gmail.com 